\title{
Polymer-metal complexes as emerging catalysts for electrochemical reduction of carbon dioxide
}

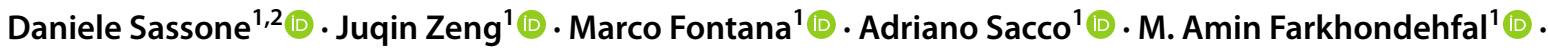 \\ Monica Periolatto ${ }^{2}$ (D) Candido F. Pirri ${ }^{1,2}$ - Sergio Bocchini ${ }^{1}(\mathbb{D}$
}

Received: 16 January 2021 / Accepted: 31 May 2021 / Published online: 21 June 2021

(c) The Author(s) 2021

\begin{abstract}
A class of metal-doped polyanilines (PANIs) was synthesized and investigated as electrocatalysts for the carbon dioxide reduction reaction $\left(\mathrm{CO}_{2} \mathrm{RR}\right)$. These materials show good affinity for the electrode substrate and allow to obtain stable binderfree electrodes, avoiding the utilization of expensive ionomer and additives. The emeraldine-base polyaniline (EB-PANI), in absence of metal dopant, shows negligible electrocatalytic activity and selectivity toward the $\mathrm{CO}_{2} \mathrm{RR}$. Such behavior significantly improves once EB-PANI is doped with an appropriate cationic metal ( $\mathrm{Mn}, \mathrm{Cu}$ or $\mathrm{Sn}$ ). In particular, the Sn-PANI outperforms other metal-doped samples, showing a good turnover frequency of $72.2 \mathrm{~h}^{-1}$ for the $\mathrm{CO}_{2} \mathrm{RR}$ at $-0.99 \mathrm{~V}$ vs the reversible hydrogen electrode and thus satisfactory activity of metal single atoms. Moreover, the Sn-PANI also displays impressive stability with a $100 \%$ retention of the $\mathrm{CO}_{2} \mathrm{RR}$ selectivity and an enhanced current density of $4.0 \mathrm{~mA} \mathrm{~cm}^{-2}$ in a 10-h test. PANI, a relatively low-cost substrate, demonstrates to be easily complexed with different metal cations and thus shows high tailorability. Complexing metal with conductive polymer represents an emerging strategy to realize active and stable metal single-atom catalysts, allowing efficient utilization of metals, especially the raw and precious ones.
\end{abstract}

\section{Graphic abstract}

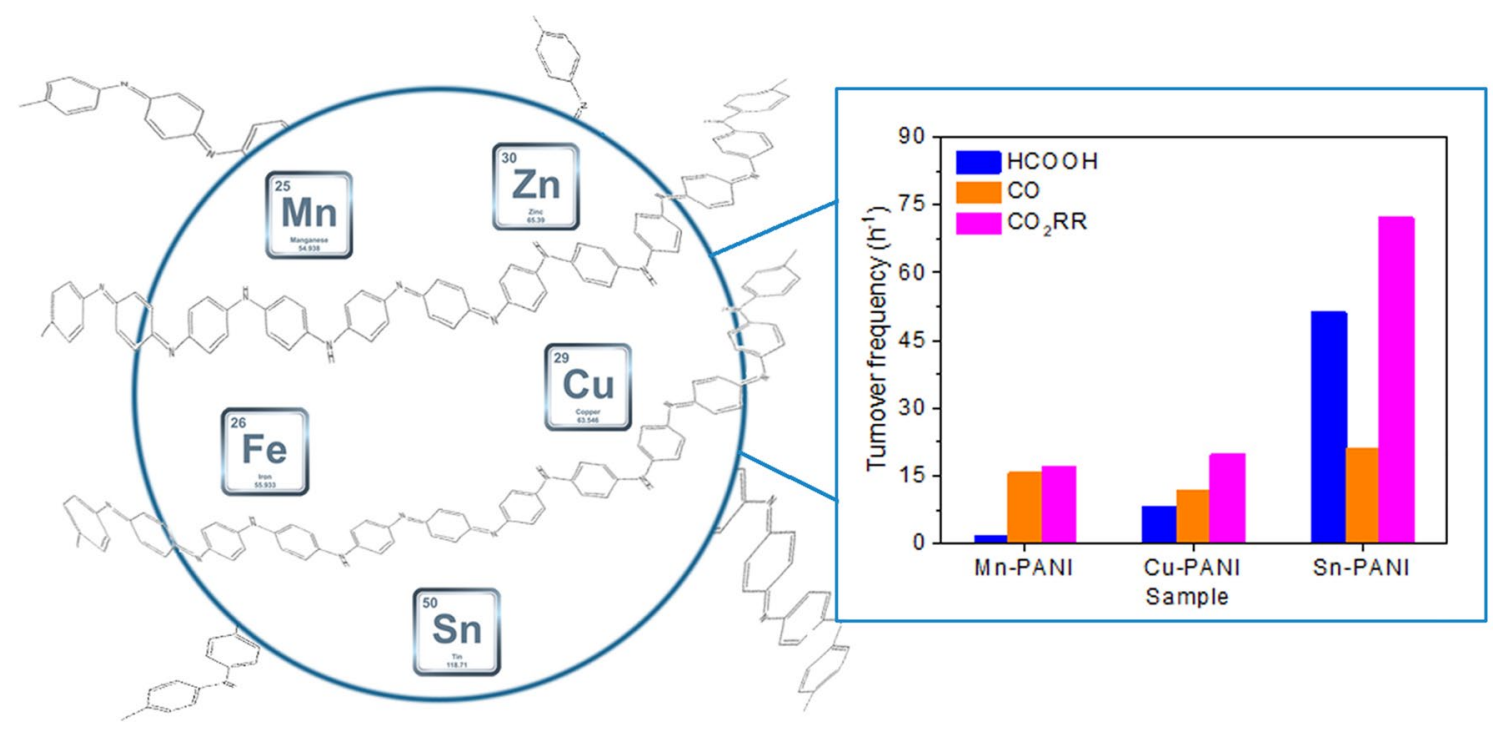

Keywords Carbon dioxide reduction $\cdot$ Electrocatalysis $\cdot$ Polyaniline $\cdot$ Single-atom catalysts $\cdot$ Stability

Juqin Zeng

juqin.zeng@iit.it

Extended author information available on the last page of the article 


\section{Introduction}

Energy consumption rapidly grows all around the world, from emerging countries with conventional industries to western society with more and more sophisticated technologies, demanding fast increase in the fossil fuels combustion and consequently boosting the $\mathrm{CO}_{2}$ emission. Conversion of $\mathrm{CO}_{2}$ into valuable chemicals and fuels is supposed to bring benefits not only to the climate and natural carbon cycle, but also to the long-term energy storage for confronting the future fossil fuel shortage [1]. Among many technologies, the electrochemical process is of great interest since it can be conducted at mild conditions using excess electricity from the grid as energy input and the products are highly tunable by utilizing different catalysts and applying various potentials. Although being very promising, the electrochemical $\mathrm{CO}_{2}$ conversion confronts many challenges due to the high energy barriers, slow kinetics and complex pathways of the $\mathrm{CO}_{2}$ reduction reaction $\left(\mathrm{CO}_{2} \mathrm{RR}\right)$. Hence, rationally designed electrocatalysts are essential to advance this technology. An ideal electrocatalyst should have high activity, good selectivity toward specific products and satisfactory stability over long-time operation. Among numerous investigated metallic electrodes [2], copper nanoparticles are uniquely able to produce $\mathrm{C}_{2}$ and $\mathrm{C}_{3}$ molecules [3-5]; silver, gold and zinc show the best selectivity for $\mathrm{CO}$ production [6-8]; p-block metals (In, $\mathrm{Sn}, \mathrm{Pb}$ ) are selective catalysts for the $\mathrm{HCOOH} / \mathrm{HCOO}^{-}$formation [9]. Significant improvements can be reached switching from mono-metal systems to rationally designed multi-metal alloys taking advantage of the synergistic effect of different metals [10-12]. Despite the promising performance, a general limit of metallic electrodes is the high price and the scarce availability of many chemical species. These materials, even in the form of nanostructures, have low active sites-to-mass ratios. Hence, it could be of vital importance to increase the utilization efficiency of the metal, especially considering that many metals are critical raw materials due to limited availability, geopolitical conflicts in the source's countries, toxicity and other factors [13]. In order to enhance the metal utilization, an ideal strategy is to constrain each single metal atom to act as active site for the reaction [14-17]. From this perspective, organometallic complexes are the best example, in which each metal cation/atom coordinates different ligands, being stabilized and enriched in electron density [18]. Those molecules are commonly used in homogeneous catalysis systems that require the catalyst dissolution in a proper solvent without being immobilized onto the working electrode. Even though high turnover number and turnover frequency values are reported, the stability of this class of molecules is often discouraging
[19]. In addition, high overpotentials could be required to form the active catalytic species and to overcome the low conductivity.

This work aims at obtaining metal single-atom catalysts with a high active sites-to-metal ratio, possessing satisfactory activity, selectivity and stability in the $\mathrm{CO}_{2} \mathrm{RR}$. Polyaniline (PANI) has been widely studied as a support for metal nanoparticles like $\mathrm{Cu}, \mathrm{Pd}$ and $\mathrm{Pt}[20,21]$, and also as a precursor for nitrogen-doped carbon materials synthesized through a pyrolysis process [22, 23]. However, it has never been investigated itself as electrocatalyst for the $\mathrm{CO}_{2} \mathrm{RR}$. It is known to be semiconductive in the non-protonated form (emeraldine base, EB-PANI) and conductive in the emeraldine protonated form (emeraldine salt, ES-PANI) [24]. The conductive PANI can also be obtained through the use of Lewis acids such as metal cations [25]. In the present work, EB-PANI and PANIs doped with various metal cations ( $\mathrm{Mn}, \mathrm{Cu}, \mathrm{Sn}$ and $\mathrm{Fe}$ ions) were synthesized and investigated for the first time as heterogeneous catalysts for the $\mathrm{CO}_{2} \mathrm{RR}$, combining the single metal atom activity typical of the homogenous molecular catalysis with the good stability of the heterogeneous catalysts.

\section{Experimental section}

\subsection{Chemicals and materials}

All reagents were purchased from commercial sources without further purification. N-phenyl-1,4-phenylenediamine (DANI, 98\%), copper (II) chloride $\left(\mathrm{CuCl}_{2}, 99 \%\right)$, iron (III) chloride $\left(\mathrm{FeCl}_{3} \cdot 6 \mathrm{H}_{2} \mathrm{O}, 97 \%\right)$, manganese (II) chloride $\left(\mathrm{MnCl}_{2}, 99 \%\right)$, tin (IV) chloride $\left(\mathrm{SnCl}_{4} \cdot 5 \mathrm{H}_{2} \mathrm{O}, 98 \%\right)$ ammoniumpersulfate (APS, $\left.\left(\mathrm{NH}_{4}\right)_{2} \mathrm{~S}_{2} \mathrm{O}_{8}, 98 \%\right)$, methanol $(\mathrm{MeOH}$, 99.9\%), N-methyl-2-pyrrolidinone (NMP, 99.5\%), hydrochloric acid fuming $(\mathrm{HCl}, 37 \%)$, potassium bromide $(\mathrm{KBr}$, $99 \%$ ), Nafion ${ }^{\mathrm{TM}} 117$ containing solution (5\% in a mixture of lower aliphatic alcohols and water) were all purchased from Merck.

\subsection{Synthesis}

The ES-PANI was synthetized by bulk polymerization using DANI (5 gr, $27.1 \mathrm{mmol}$ ) as monomer and APS (9.29 gr, $40.7 \mathrm{mmol}$ ) as oxidizing agent in $20 \mathrm{~mL}$ of solution $70: 30$ v/v $\mathrm{MeOH}: \mathrm{H}_{2} \mathrm{O}$ with $1 \%$ w/w of $\mathrm{HCl}$. DANI was dissolved in $15 \mathrm{~mL}$ of the starting solution and placed in an ice bath under stirring, while APS was dissolved in the remaining $5 \mathrm{~mL}$ of the starting solution. Then, the APS solution was slowly added dropwise into the DANI solution in 5 min and kept under stirring for $3 \mathrm{~h}$ at room temperature (RT). The obtained dark green precipitate was filtered, washed several times with a solution 70:30 MeOH: $\mathrm{H}_{2} \mathrm{O}$ (in order to dissolve the low molecular 
weight polymers) and then dried at $60{ }^{\circ} \mathrm{C}$. In order to obtain EB-PANI, the powder was dispersed in $40 \mathrm{~mL}$ of ammonia $32 \%$ solution and stirred overnight, then filtered and washed with water several times and dried overnight at $60{ }^{\circ} \mathrm{C}$. Doping reaction was performed dissolving $100 \mathrm{mg}$ (around $1 \mathrm{mmol}$ ) of EB-PANI and $11 \mathrm{mmol}$ of the relative metal salt $\left(\mathrm{MnCl}_{2}\right.$, $\mathrm{CuCl}_{2}, \mathrm{SnCl}_{4} \cdot 6 \mathrm{H}_{2} \mathrm{O}$ or $\mathrm{FeCl}_{3}$ ) in $20 \mathrm{~mL}$ of $\mathrm{MeOH}$ and stirred at $60{ }^{\circ} \mathrm{C}$ overnight. The solution was then diluted in water to promote the metal-PANI precipitation. The obtained precipitate was thus filtered, washed several times with water in order to remove any residual trace salts, and then dried overnight at $60{ }^{\circ} \mathrm{C}$.

\subsection{Physical and chemical characterizations}

Fourier-transform infrared spectroscopy (FT-IR) analysis was performed using $\mathrm{KBr}$ pellets on a Bruker Tensor II in transmission mode. The pellets were prepared grinding $1 \mathrm{mg}$ of sample with $200 \mathrm{mg}$ of anhydrous $\mathrm{KBr}$ and then compacting with a pressure of 10 ton $\mathrm{cm}^{-1}$.

Inductively coupled plasma-mass spectroscopy (ICP-MS) analysis was performed on an Icap Q ICP-MS (Thermo Fisher) and the data were collected and processed by the related Thermo Fischer ICP software.

UV-Vis spectroscopy was performed with a Perkin-Helmer UV/Vis/NIR spectrometer LAMBDA ${ }^{\mathrm{TM}} 650 \mathrm{~S}$ in absorption mode. Each sample (1 mg) was dissolved in NMP (5 mL) to prepare the solution. Blank solvent spectrum was subtracted from each recorded spectrum.

Field-emission scanning electron microscopy (FESEM) characterization was performed on a ZEISS Supra 40 FESEM microscope.

X-ray photoelectron spectroscopy (XPS) analysis was performed with a PHI 5000 Versaprobe spectrometer (Physical Electronics), equipped with monochromatic Al K-alpha $\mathrm{X}$-ray source $(1486.6 \mathrm{eV})$. Surface charge compensation was obtained with a combined system, based on an electron gun and $\mathrm{Ar}^{+}$ion gun. Survey and high-resolution (HR) spectra were acquired using pass energy (PE) values of 187.85 and $23.50 \mathrm{eV}$, respectively. The calibration of the binding energy (BE) scale was obtained by setting the $\mathrm{C}-\mathrm{C} \mathrm{sp}^{2}$ component of the $\mathrm{C} 1 \mathrm{~s}$ region to $284.5 \mathrm{eV}$. Casa XPS software was used for the analysis of the experimental data. The Shirley background function was subtracted from HR spectra to remove the background signal [26]. The reported uncertainties on relative atomic concentrations were calculated with Monte Carlo routines implemented in Casa XPS.

\subsection{Electrochemical characterization}

\subsubsection{Preparation of electrodes}

The as-prepared catalysts were coated onto a carbon paper (gas diffusion layer, GDL; SIGRACET 28BC, SGL Technologies) to obtain electrodes. To prepare a binder-free electrode, $1 \mathrm{mg}$ of catalyst (EB-PANI, Cu-PANI, SnPANI, Mn-PANI or Fe-PANI) was dispersed in $160 \mu \mathrm{L}$ of ethanol by sonication. The obtained uniform slurry was then drop-casted on the GDL and dried in air overnight. Each electrode has a catalyst loading of $0.7 \mathrm{mg} \mathrm{cm}^{-2}$. To study the composition effect on the $\mathrm{CO}_{2} \mathrm{RR}$, four $\mathrm{Cu}$-PANI electrodes with various compositions were prepared: (i) a free-standing one with only catalyst, (ii) a second one with the addition of $0.3 \mathrm{mg}$ of carbon black (CB, Shawinigan Black AB50), (iii) a third one with the addition of $40 \mu \mathrm{L}$ of Nafion solution (Nafion ${ }^{\circledR} 117$ solution, 5 wt. \%) and (iv) the last one with the addition of both $\mathrm{CB}(0.3 \mathrm{mg})$ and Nafion solution $(40 \mu \mathrm{L})$.

\subsubsection{Cyclic voltammetry (CV) and electrochemical impedance spectroscopy (EIS)}

The electrochemical characterization was firstly performed through CV and EIS in a three-electrode H-type cell at RT with a Metrohm Multi Autolab/M101 potentiostat. The working electrode was a catalyst-coated carbon paper with a geometric area of $0.15 \mathrm{~cm}^{2}$. A Pt wire was used as counter electrode and an $\mathrm{Ag} / \mathrm{AgCl}(3 \mathrm{M} \mathrm{NaCl})$ was used as reference electrode. A membrane (Nafion ${ }^{\mathrm{TM}}$ Membrane N117, Sigma-Aldrich) was employed to separate the cathodic and anodic compartments. CV measurements were performed from 0.73 to $-1.07 \mathrm{~V}$ vs Reference Hydrogen Electrode (RHE) at a scan rate of $10 \mathrm{mV} \mathrm{s}^{-1}$ in $\mathrm{N}_{2}$ - and $\mathrm{CO}_{2}$-saturated/purged $\left(5 \mathrm{~mL} \mathrm{~min}^{-1}\right)$ $0.1 \mathrm{M} \mathrm{KHCO}_{3}$ aqueous solution. Unless otherwise specified, all the potentials refer to RHE in this work. The potential applied versus $\mathrm{Ag} / \mathrm{AgCl}$ was converted to that versus RHE using the formula $\mathrm{E}$ (vs RHE) $=\mathrm{E}$ (vs Ag/ $\mathrm{AgCl})+0.197 \mathrm{~V}+0.0591 \times \mathrm{pH}$. To determine the doublelayer capacitance of the electrode, $\mathrm{CV}$ was executed in a potential range of $-0.24 \mathrm{~V}$ to $-0.39 \mathrm{~V}$ at scan rates of $2 \mathrm{mV} \mathrm{s}^{-1}, 5 \mathrm{mV} \mathrm{s}^{-1}, 10 \mathrm{mV} \mathrm{s}^{-1}, 25 \mathrm{mV} \mathrm{s}^{-1}, 50 \mathrm{mV} \mathrm{s}^{-1}$, $75 \mathrm{mV} \mathrm{s}^{-1}$ and $100 \mathrm{mV} \mathrm{s}^{-1}$ in the $\mathrm{N}_{2}$-saturated $0.1 \mathrm{M}$ $\mathrm{KHCO}_{3}$ aqueous solution. EIS measurements were performed at various potentials from $-0.19 \mathrm{~V}$ to $-0.99 \mathrm{~V}$ with an AC signal of $10 \mathrm{mV}$ of amplitude and $1-10^{5} \mathrm{~Hz}$ frequency range in $\mathrm{N}_{2}$ - and $\mathrm{CO}_{2}$-saturated $0.1 \mathrm{M} \mathrm{KHCO}_{3}$ aqueous solutions. 


\subsubsection{Chronoamperometric (CA) measurement and product analysis}

CA tests were performed with a CHI 760D (CH Instruments, Inc.) potentiostat in a customized H-type EC cell (ElectroCell ${ }^{\mathrm{TM}}$, Scheme S1) in order to study the $\mathrm{CO}_{2} \mathrm{RR}$ and to quantify the products. A catalyst-coated carbon paper of $1.5 \mathrm{~cm}^{2}$ was used as the working electrode, a platinum foil as the counter and an $\mathrm{Ag} / \mathrm{AgCl}$ (1 mm, leak-free LF-1) as the reference. Gas-phase products were analyzed on-line by a micro gas chromatograph ( $\mu \mathrm{GC}$, Fusion $\AA$, INFICON) with two channels containing a $10 \mathrm{~m}$ Rt-Molsieve $5 \mathrm{~A}$ column and an $8 \mathrm{~m} \mathrm{Rt}-\mathrm{Q}-$ Bond column, respectively. Both channels are equipped with a micro thermal conductivity detector (microTCD). The inlet of the $\mu \mathrm{GC}$ equipment was connected to the cathodic side of the electrochemical cell through a GENIE filter to remove the humidity from the gas. During the CA measurements, a constant $\mathrm{CO}_{2}$ flow rate of $10 \mathrm{~mL} \mathrm{~min}^{-1}$ was maintained to saturate the electrolyte and to carry out the gaseous products to the $\mu \mathrm{GC}$. Liquid products were analyzed by a High-Performance Liquid Chromatograph (Thermo Scientific Ultimate3000 HPLC) with a UV-Vis Detector set at $210 \mathrm{~nm}$ using a ReproGel $(300 \times 8 \mathrm{~mm})$ column, with $9.0 \mathrm{mM} \mathrm{H}_{2} \mathrm{SO}_{4}$ (flow rate of $1.0 \mathrm{~mL} \mathrm{~min}^{-1}$ ) as mobile phase. The faradaic efficiency (FE) for each product was calculated by dividing the coulombs needed to produce the actual determined amount of this product by the total coulombs consumed during a corresponding reduction period.

\section{Results and discussion}

\subsection{Physical and chemical properties of the samples}

FT-IR was performed to study the correct polymerization of EB-PANI and metal-doped PANI samples. A typical absorption pattern of polyaniline is observed for the ES-PANI (Figure S1) and it is preserved for the EB-PANI and metaldoped samples (Fig. 1). EB-PANI shows the characteristic $\nu_{\mathrm{N}-\mathrm{H}}$ at $3172 \mathrm{~cm}^{-1}$ stretching of secondary amines, the $\nu_{\mathrm{C}-\mathrm{H}}$ at $3031 \mathrm{~cm}^{-1}$ stretching of aromatic rings, the $\nu_{\mathrm{C}-\mathrm{N}}$ at $1597 \mathrm{~cm}^{-1}$ of the benzenoid ring and the $\nu_{\mathrm{C}-\mathrm{C}}$ at $1495 \mathrm{~cm}^{-1}$ stretching of the quinoid ring of the polymer chain, the $\nu_{\mathrm{C}-\mathrm{N}}$ at $1312 \mathrm{~cm}^{-1}$ stretching of aromatic amines, the quinoid ring stretching at $1151 \mathrm{~cm}^{-1}$, and the out of plane bending of para-disubstituted benzene at $819 \mathrm{~cm}^{-1}$. Similar patterns are recorded for the metal-doped PANI samples, indicating good preservation of the polymer chains during the doping reaction.

Successful incorporation of metal elements is confirmed by ICP-MS and XPS analysis. Figure S2 reports representative survey spectra for all the analyzed samples, alongside labels for the most intense peaks related to the detected

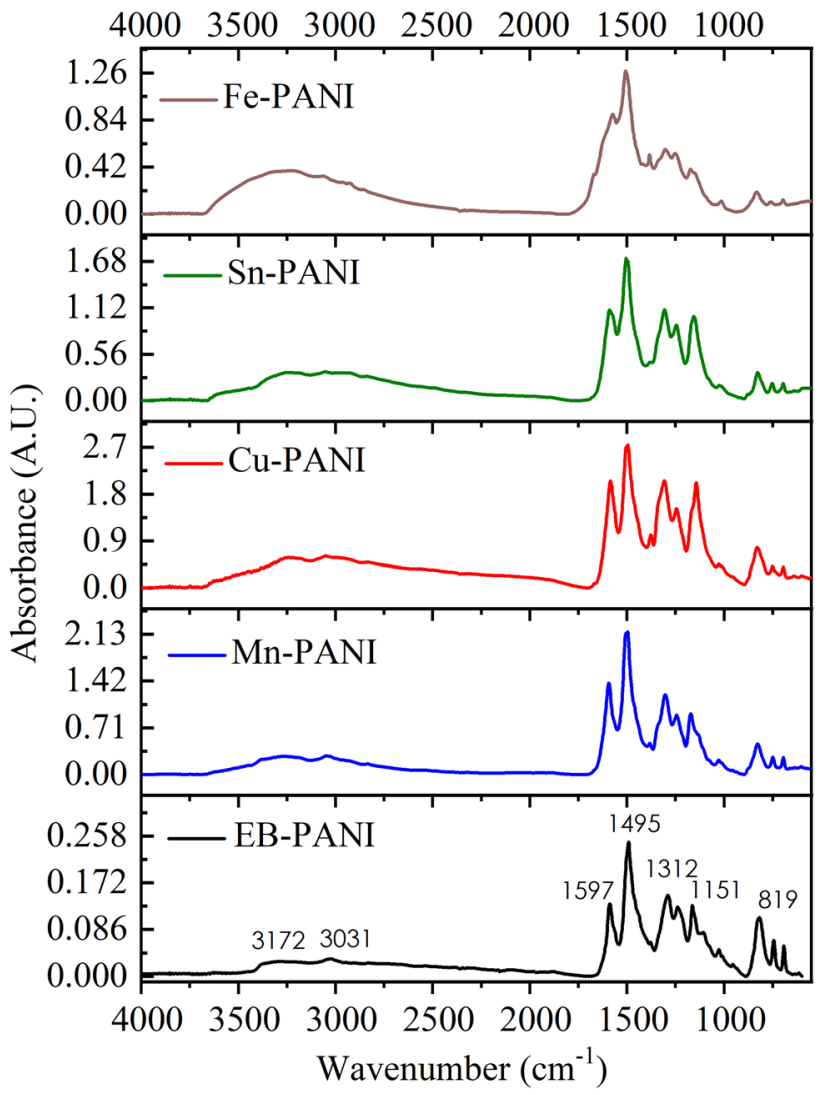

Fig. 1 FT-IR spectra of EB-PANI and metal-doped PANI samples

chemical elements. The weight percentage of doped metal and the atomic ratio of metal to coordinated nitrogen were quantified and listed in Table 1. It is confirmed that the chemical composition of the synthesized EB-PANI is in accordance with the reported molecular structure [27, 28], alongside slight oxidation and residual chlorine content from the polymerization process.

High-resolution XPS studies further provide information on the oxidation state of the metal cations. For Cu-PANI sample (Fig. 2a), the $\mathrm{Cu} 2 \mathrm{p}_{3 / 2}$ peak can be deconvoluted into two main contributions at $932.6 \mathrm{eV}(75.6 \%$ peak area) and $934.6 \mathrm{eV}$ (24.4\% peak area), which can be attributed to $\mathrm{Cu}(\mathrm{I})$ and $\mathrm{Cu}(\mathrm{II})$, respectively, in accordance with the literature on $\mathrm{CuCl}$ [29], $\mathrm{CuCl}_{2}$ [30] and $\mathrm{Cu}$-doped polyaniline [31]. Based on the $\mathrm{Sn} 3 \mathrm{~d}_{5 / 2}$ peak position $(487.3 \mathrm{eV})$, it is possible to exclude the presence of metallic Sn in the Sn-PANI sample (Fig. 2b), while it is difficult to define the exact oxidation state (IV or II) of the Sn cations, due to the low sensitivity of the binding energy on the oxidation state of Sn [32]. Concerning the Mn-PANI sample (Fig. 2c), the identification of the oxidation state of $\mathrm{Mn}$ is not straightforward due to its low concentration and the well-known complexity of interpretation of the $\mathrm{Mn} 2 \mathrm{p}$ region caused by multipletsplitting and satellite structure [33]. Based on the estimated 
Table 1 Metal percentage by ICP quantification and chemical composition by semiquantitative high-resolution XPS analysis

\begin{tabular}{|c|c|c|c|c|c|c|c|}
\hline \multirow[t]{2}{*}{ Sample } & \multirow{2}{*}{$\begin{array}{l}\text { ICP } \\
\text { Metal } \\
(w t \%)\end{array}$} & \multicolumn{6}{|l|}{$\mathrm{XPS}^{\mathrm{a}}$} \\
\hline & & $\begin{array}{l}\mathrm{C} \\
(\mathrm{at} \%)\end{array}$ & $\begin{array}{l}\mathrm{O} \\
\text { (at\%) }\end{array}$ & $\begin{array}{l}\mathrm{N} \\
(\mathrm{at} \%)\end{array}$ & $\begin{array}{l}\mathrm{Cl} \\
\text { (at\%) }\end{array}$ & $\begin{array}{l}\text { Metal } \\
\text { (at\%) }\end{array}$ & $\begin{array}{l}\text { Metal/N } \\
\text { (at\%/at\%) }\end{array}$ \\
\hline EB-PANI & l & $80.5(4) \pm 0.4$ & 3.9 (2) \pm 0.2 & $15.2(4) \pm 0.4$ & 0.4 & & I \\
\hline Cu-PANI & $8.9 \pm 1.6$ & $78.3(7) \pm 1.1$ & $6.2(3) \pm 0.3$ & $12.3(6) \pm 1.2$ & 2.5 & $10.7(1) \pm 0.1$ & $0.06(1)$ \\
\hline Sn-PANI & $6.6 \pm 1.1$ & $71.5(5) \pm 0.5$ & $9.8(3) \pm 0.3$ & $11.2(5) \pm 0.5$ & 4.7 & $12.8(1) \pm 0.1$ & $0.25(1)$ \\
\hline Mn-PANI & $2.2 \pm 1.0$ & $80.1(4) \pm 0.5$ & $5.0(2) \pm 0.2$ & $12.9(5) \pm 0.5$ & 1.5 & $10.5(1) \pm 0.1$ & $0.04(1)$ \\
\hline Fe-PANI & $1.4 \pm 1.0$ & $72.0(4) \pm 0.5$ & $13.8(2) \pm 0.2$ & $8.6(3) \pm 0.5$ & 4.6 & $11.1(1) \pm 0.1$ & $0.13(1)$ \\
\hline
\end{tabular}

a The uncertainties on the relative atomic concentrations are reported in brackets and they refer to the last digit (a)

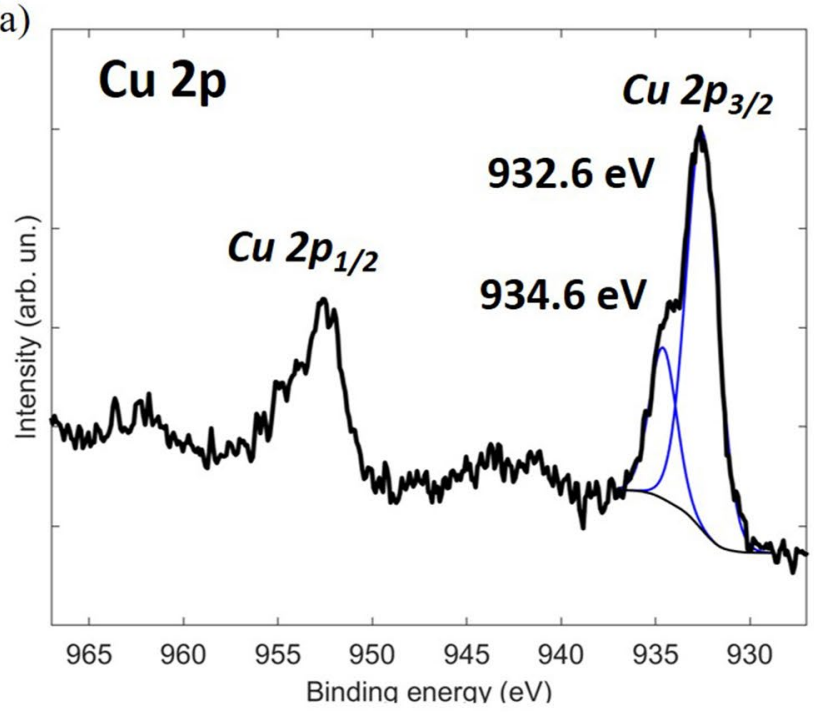

(c)

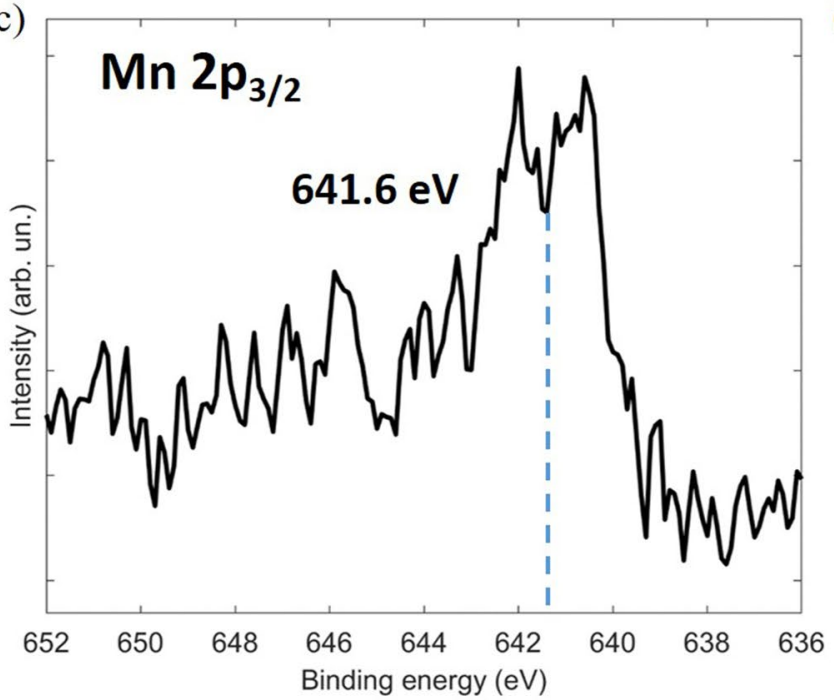

(b)

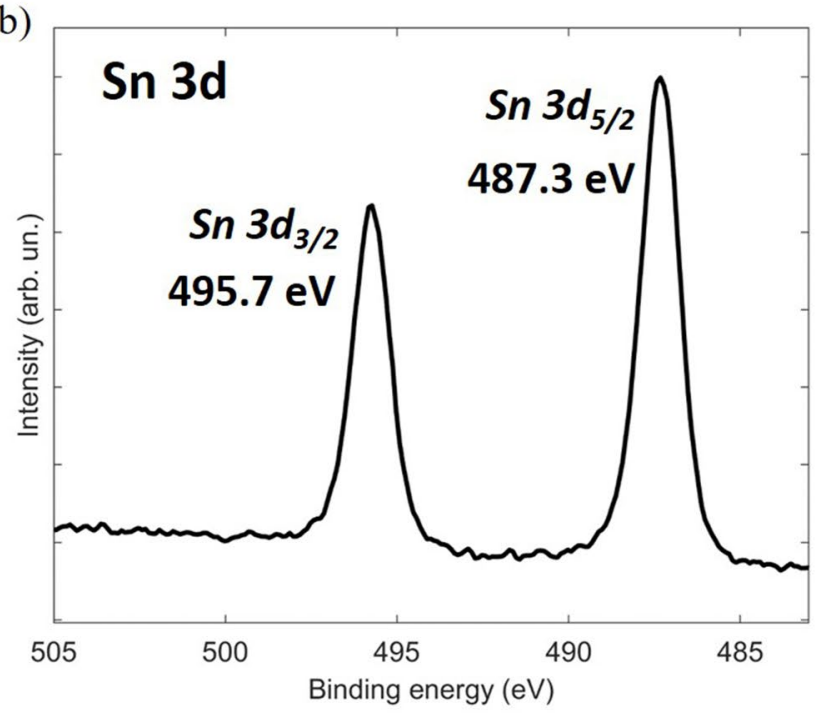

(d)

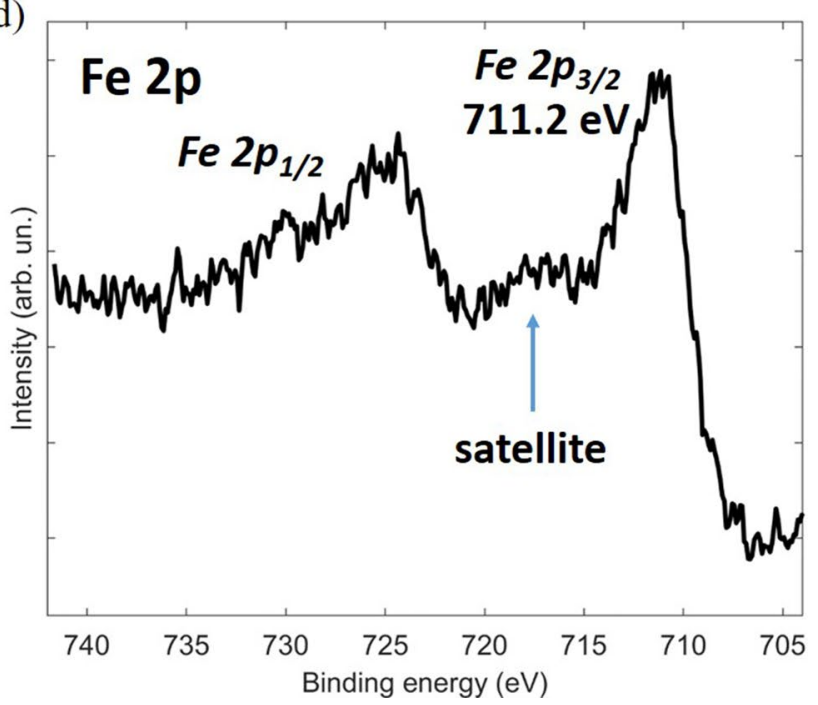

Fig. 2 High-resolution XPS acquisitions of the Cu2p, Sn3d, Mn2 $\mathrm{p}_{3 / 2}$ and Fe2p regions for samples a Cu-PANI, b Sn-PANI, c Mn-PANI and d Fe-PANI 


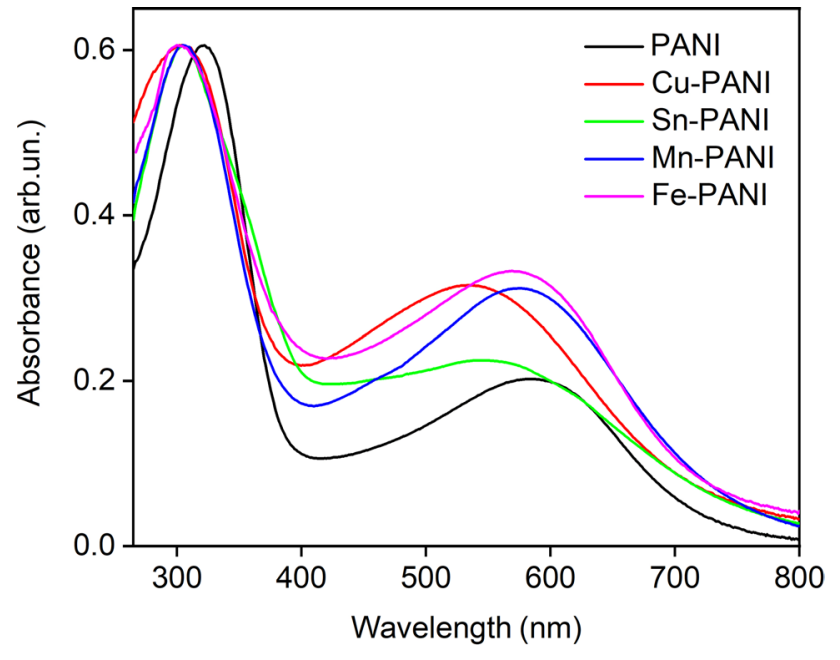

Fig. 3 Normalized UV-Vis spectra of PANI-based samples dissolved in NMP solution

binding energy of the $\mathrm{Mn} 2 \mathrm{p}_{3 / 2}$ peak $(641.6 \mathrm{eV})$, the presence of $\mathrm{Mn}(\mathrm{III})$ and $\mathrm{Mn}(\mathrm{IV})$ seems most probable [34]. Regarding the Fe-PANI sample (Fig. 2d), both the Fe2 $\mathrm{p}_{3 / 2}$ peak at a binding energy of $711.2 \mathrm{eV}$ and the presence of characteristic satellite, point to $\mathrm{Fe}(\mathrm{III})$, in accordance with the literature on $\mathrm{FeCl}_{3}$ [35] and $\mathrm{Fe}$-doped polyaniline [36]. Concisely, detailed XPS analysis unveils that $\mathrm{Cu}, \mathrm{Sn}, \mathrm{Mn}$ and Fe ions are successfully introduced in the EB-PANI as coordinated ions.

The UV-Vis spectra of various samples, normalized based on the as-obtained data, are shown in Fig. 3. Two transitions, the $\pi-\pi^{*}$ between 300 and $400 \mathrm{~nm}$ associated with the benzoid moiety absorption, and the $\pi$-polaron between 500 and $700 \mathrm{~nm}$ related to the bipolar formation, are present for EB-PANI. The spectra of metal-doped samples resemble the one recorded for EB-PANI, in agreement with the literature [37]. The absorption peaks are slightly different for each sample: $322 \mathrm{~nm}\left(\pi-\pi^{*}\right)$ and $585 \mathrm{~nm}(\pi$-polaron) for EB-PANI, $305 \mathrm{~nm}$ and $534 \mathrm{~nm}$ for Cu-PANI, $305 \mathrm{~nm}$ and $548 \mathrm{~nm}$ for Sn-PANI, $305 \mathrm{~nm}$ and $574 \mathrm{~nm}$ for Mn-PANI,
$300 \mathrm{~nm}$ and $569 \mathrm{~nm}$ for Fe-PANI. It is interesting to note that the presence of metal cations leads to a hypsochromic shift (blue shift) for both $\pi-\pi^{*}$ and $\pi$-polaron transitions and causes an increase in the $\pi$-polaron absorption, evidencing that a doping process is involved at different scales for each cations [38]. The presence of cations indicates the formation of a metal complex and its chemical composition is influenced by the anion specie of the metal precursor. In the case of halogen metals, the anion is still present in the metal complex as halogen ligand due to its favorable coordinative properties, as evidenced by XPS result (Table 1), while less coordinative anions such as nitrate could result in more complexation for the polyanilines [39].

Further study on the morphology has been performed by FESEM. As shown in Fig. 4, Sn-PANI preserves the morphology of EB-PANI without the presence of newly formed nanostructures. Similar morphology is also observed for $\mathrm{Cu}-, \mathrm{Mn}-$ and Fe-PANI (Figure S3). This outcome indicates the successful doping of metal cations in the PANI matrix, in consistence with XPS and UV-Vis analysis.

\subsection{Investigation of the electrode composition}

To enable the electrochemical evaluation of the powderlike materials toward the $\mathrm{CO}_{2} \mathrm{RR}$, the as-prepared catalysts are usually coated onto a carbon paper to obtain the electrodes. In the literature, one commonly underestimated but crucial aspect is the composition of the electrode. Unlike in other research fields such as fuel cells, where the electrode composition has already been intensively studied, the investigation on the electrode fabrication for the $\mathrm{CO}_{2} \mathrm{RR}$ is still not mature. In the literature, several methods are reported for the electrode preparation [40], while a specific study on the composition and the roles of each component is still missing. Generally, electrode fabrication requires a current collector that is usually a metal or carbon-based conductive substrate, a catalyst that is dispersed on the collector to maximize the accessibility, a binder that immobilizes the catalyst on the collector and other additives for
Fig. 4 FESEM images of a EBPANI and $\mathbf{b}$ Sn-PANI
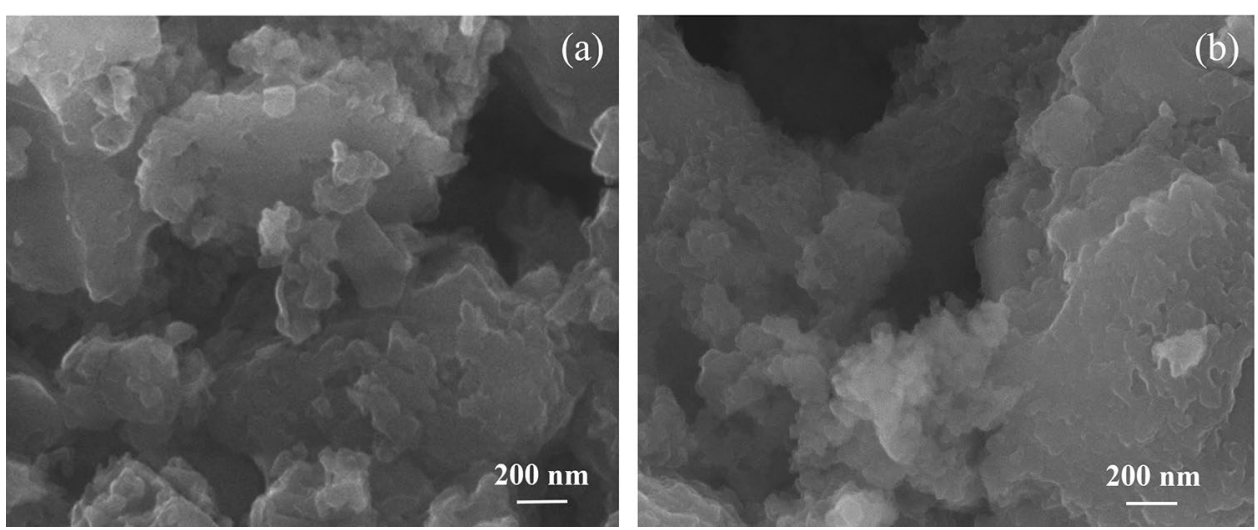

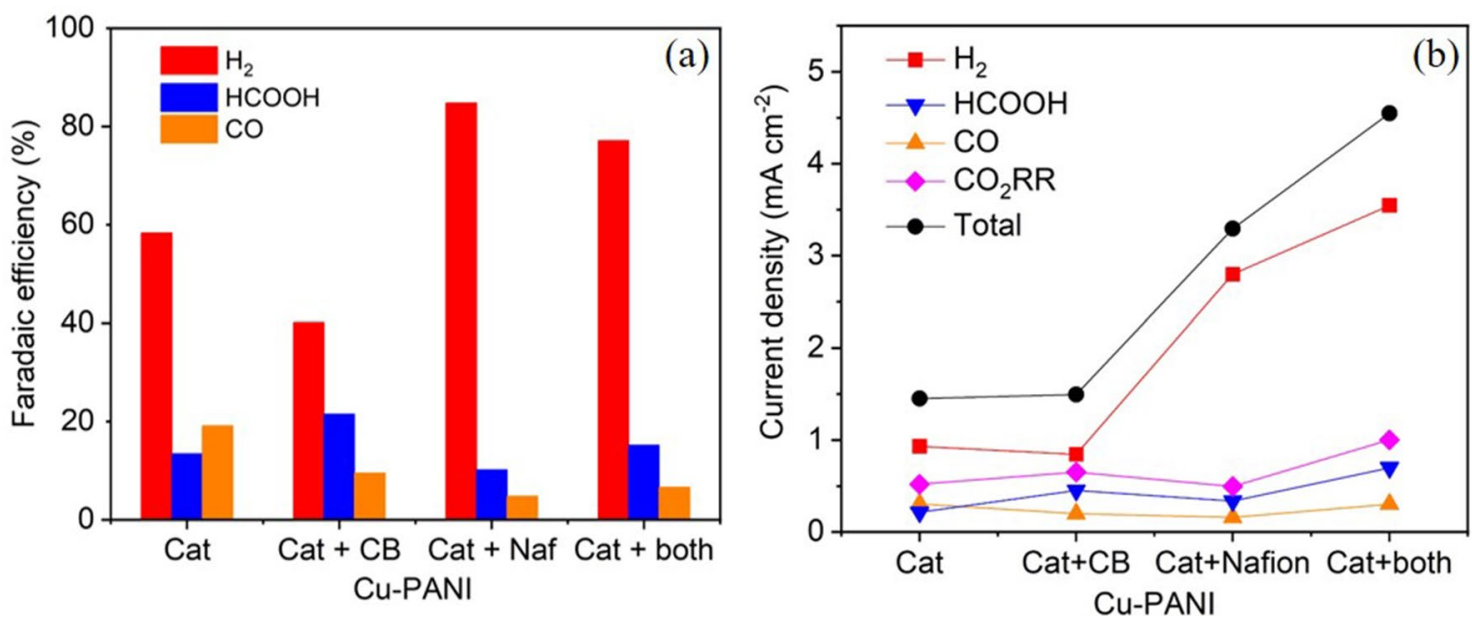

Fig. $5 \mathrm{CO}_{2} \mathrm{RR}$ on various electrodes with different compositions at $-0.99 \mathrm{~V}$ in $\mathrm{CO}_{2}$-saturated $0.1 \mathrm{M} \mathrm{KHCO}_{3}$ electrolyte: a Faradaic efficiencies and $\mathbf{b}$ partial current densities

enhancing the electrical contact or the ionic conductivity. In the $\mathrm{CO}_{2} \mathrm{RR}$, commercial carbon papers (equipped with GDL) are commonly used as the current collector and carbon blacks (CBs) are widely employed to enhance the electrical conductivity in the $\mathrm{CO}_{2} \mathrm{RR}$. Another commonly used additive is Nafion, an ionomer that acts both as a binder and as an ionic conductor. In order to study the effect of the individual components on the $\mathrm{CO}_{2} \mathrm{RR}$, we performed a cross investigation on various electrodes, including one containing only the catalyst (Cu-PANI), one containing $\mathrm{Cu}-\mathrm{PANI}$ and $\mathrm{CB}$, one containing $\mathrm{Cu}-\mathrm{PANI}$ and Nafion, and a last one containing $\mathrm{Cu}-\mathrm{PANI}, \mathrm{CB}$ and Nafion, as shown in Fig. 5. Interestingly, Nafion addition dramatically favors the hydrogen evolution reaction (HER) in terms of both selectivity (higher $\mathrm{FE}_{\mathrm{H} 2}$ ) and electrode activity (higher partial current density, $\mathrm{j}_{\mathrm{H} 2}$ ), while it does not influence the electrode activity of the $\mathrm{CO}_{2} \mathrm{RR}$. It is believed that the fluorinated groups of the ionomer could increase the hydrophobicity of the electrode and promote the selectivity toward the reduction of $\mathrm{CO}_{2}$ rather than protons [41]. However, the terminal chain sulfonic groups in Nafion lead to an increase in the overall surface polarity [27], resulting in the enhancement in the HER. The co-presence of Nafion and CB further enhances the HER activity, while $\mathrm{CB}$ alone does not add any significant beneficial effect for the $\mathrm{CO}_{2} \mathrm{RR}$ (Fig. 5b). Based on the above analysis, it is considered unfavorable to fabricate electrodes with Nafion addition, and it is even more disadvantageous taking into account the high price of commercially available Nafion solution. PANI is an ionomer itself and can act as an ionic conductor. It also shows great affinity for the GDL substrate without a binder. Hence, it is encouraging that the PANI-based electrodes can be fabricated without any additives.

\subsection{Electrochemical performances of various metal-doped PANI samples}

The catalytic properties of EB-, $\mathrm{Mn}-, \mathrm{Cu}-, \mathrm{Sn}-$, and Fe-PANI binder-free electrodes were investigated at $-0.79 \mathrm{~V}$ and - $0.99 \mathrm{~V}$. Fe-PANI shows a $\mathrm{FE}_{\mathrm{H} 2}$ of $100 \%$, even though the highest current densities of 4.9 and $8.8 \mathrm{~mA} \mathrm{~cm}^{-2}$ are obtained at -0.79 and $-0.99 \mathrm{~V}$, respectively (Figure S4 and S5). Figure S6a compares the selectivity of EB-, Mn-, $\mathrm{Cu}$ - and Sn-PANI for the $\mathrm{CO}_{2} \mathrm{RR}$ at $-0.79 \mathrm{~V}$. It is noticed that PANI alone shows a FE of $2.8 \%$ for $\mathrm{HCOOH}$ formation. The $\mathrm{FE}_{\mathrm{HCOOH}}$ is enhanced to about $9.1 \%$ for $\mathrm{Cu}-$ and $\mathrm{Sn}-$ PANI. CO is observed on all three metal-doped PANI electrodes, with $\mathrm{FE}_{\mathrm{CO}}$ values of $2.5-7.3 \%$. The $\mathrm{CO}_{2} \mathrm{RR}$ activity of EB-PANI electrode is significantly enhanced with $\mathrm{Cu}$ and Sn-doping, as evidenced by higher current densities for the $\mathrm{CO}$ and $\mathrm{HCOOH}$ production (Figure S6b). This outcome is in good agreement with the cyclic voltammetry and electrochemical impedance spectroscopy analysis (Figure S7 and S8). Doping of PANI with Fe ions leads to the highest electrode activity, while it results in no selectivity for the $\mathrm{CO}_{2} \mathrm{RR}$, as evidenced by a much lower charge transfer resistance in $\mathrm{N}_{2}$-purged electrolyte than in the $\mathrm{CO}_{2}$-saturated one at the same potential. In contrast, the PANI doped with $\mathrm{Cu}$ or Sn ions shows enhancement not only on the electrode activity, but also on the $\mathrm{CO}_{2} \mathrm{RR}$ selectivity, as evidenced by the charge transfer resistance values obtained in $\mathrm{CO}_{2}$-saturated electrolyte, which are similar or lower with respect to those obtained in $\mathrm{N}_{2}$-purged solution [12].

Detailed analysis has been performed at $-0.99 \mathrm{~V}$ and shown in Fig. 6. As at $-0.79 \mathrm{~V}$, the EB-PANI shows a selectivity only for $\mathrm{HCOOH}$ formation with a FE of 3.6\% at $-0.99 \mathrm{~V}$ (Fig. 6a). While all $\mathrm{Mn}, \mathrm{Cu}$ and Sn dopants 

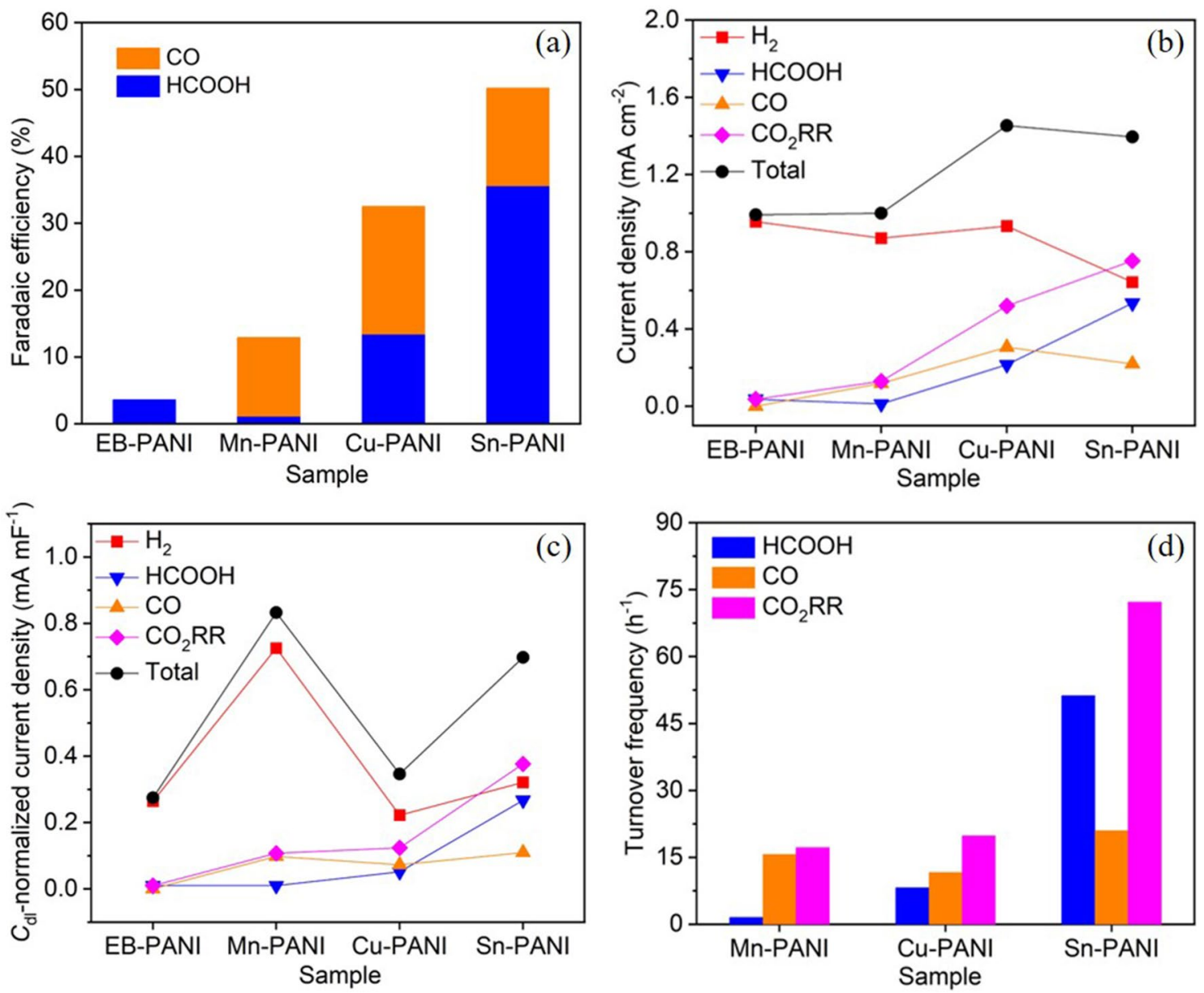

Fig. $6 \mathrm{CO}_{2} \mathrm{RR}$ on various electrodes in $\mathrm{CO}_{2}$-saturated $0.1 \mathrm{M} \mathrm{KHCO}_{3}$ electrolyte at $-0.99 \mathrm{~V}$ : a Faradic efficiencies for $\mathrm{CO}_{2} \mathrm{RR}$ products, b partial current densities, $\mathbf{c}$ double-layer capacitance-normalized partial current densities and $\mathbf{d}$ turnover frequency for $\mathrm{CO}$ and $\mathrm{HCOOH}$ products

lead to a significant enhancement in the $\mathrm{CO}_{2} \mathrm{RR}$ selectivity, the individual selectivity for $\mathrm{CO}$ or $\mathrm{HCOOH}$ formation is distinct. The Mn-PANI achieves a $\mathrm{FE}_{\mathrm{CO}}$ of $11.8 \%$ and a small $\mathrm{FE}_{\mathrm{HCOOH}}$ of $1.1 \%$. The $\mathrm{Cu}-\mathrm{PANI}$ enhances both the $\mathrm{CO}$ and $\mathrm{HCOOH}$ formation, with $\mathrm{FE}_{\mathrm{CO}}$ and $\mathrm{FE}_{\mathrm{HCOOH}}$ values of $19.1 \%$ and $13.4 \%$, respectively. The Sn-PANI shows a significant increase in the $\mathrm{FE}_{\mathrm{HCOOH}}(35.6 \%)$ and a modest $\mathrm{FE}_{\mathrm{CO}}$ of $14.6 \%$. Concisely, Mn-PANI is more selective for the CO and Sn-PANI is more selective for the $\mathrm{HCOOH}$, while $\mathrm{Cu}$-PANI produces $\mathrm{CO}$ and $\mathrm{HCOOH}$ almost equally. Figure $6 \mathrm{~b}$ shows the electrode activity of various samples in terms of geometric current density. In general, the electrode activity of PANI can be enhanced by metal doping. The total current density on various electrodes follows the trend $\mathrm{PANI} \approx \mathrm{Mn}$-PANI $<$ Sn-PANI $<\mathrm{Cu}$-PANI at $-0.99 \mathrm{~V}$. The PANI electrode shows almost no partial current density for $\mathrm{CO}$ formation, while the metal doping significantly improves the $\mathrm{CO}$ formation, with a highest value of $0.3 \mathrm{~mA} \mathrm{~cm}^{-2}$ at the $\mathrm{Cu}$-PANI electrode. $\mathrm{HCOOH}$ formation is remarkably enhanced on the Cu-PANI and Sn-PANI electrodes with respect to the PANI one. $\mathrm{CO}$ and $\mathrm{HCOOH}$ are the only detected $\mathrm{CO}_{2} \mathrm{RR}$ products and the production rate of the $\mathrm{C}_{1}$ products $(\mathrm{CO}+\mathrm{HCOOH})$ displays the trend $\mathrm{Sn}-\mathrm{PANI}>\mathrm{Cu}-$ PANI $>$ Mn-PANI $>$ PANI. These results demonstrate that the $\mathrm{Cu}$ - and Sn-doping have successfully modified the properties of PANI toward the $\mathrm{CO}_{2} \mathrm{RR}$.

The current normalized by the geometric surface area of the electrodes does not reflect the intrinsic activity of a catalyst. To evaluate the intrinsic activity of these materials, the current density is normalized by the electrochemically active surface area (ECSA). Since the ECSA is considered to be proportionally associated to the double-layer capacitance $\left(C_{\mathrm{dl}}\right)$, the intrinsic activity of various materials are compared by investigating the $C_{\mathrm{dl}}$-normalized current densities at the electrodes. As detailed in the supporting information and shown in Figure S9, the $C_{\mathrm{dl}}$ values are found to be 3.6, 1.2, 4.3 and $2.0 \mathrm{mF} \mathrm{cm}^{-2}$ for EB-PANI, Mn-PANI, Cu-PANI and Sn-PANI electrodes, respectively. As shown in Fig. 6c, doping the PANI with a metal leads to an increase in the activity of the materials for reduction reactions, including 
HER and $\mathrm{CO}_{2} \mathrm{RR}$. It is observed that the Mn-PANI shows the highest activity and the Cu-PANI has the lowest activity among the metal-doped samples. However, most of the activity of the Mn-PANI is attributed to the HER, leading to a comparable activity for the $\mathrm{CO}_{2} \mathrm{RR}$ with respect to the $\mathrm{Cu}$ PANI, and even a lower activity compared to the Sn-PANI sample. While the activity for CO formation is comparable at the three doped catalysts, the $\mathrm{HCOOH}$ formation is much more favorable on the Sn-PANI than on the others. It is also worth to note that the HER activity becomes inferior to $\mathrm{CO}_{2} \mathrm{RR}$ for Sn-PANI, which is correlated with the low activity of p-group metals for the HER [42]. Figure 6d compares the $\mathrm{CO}$ and $\mathrm{HCOOH}$ formation rates normalized by the total metal atoms, that is turnover frequency (TOF, $\mathrm{h}^{-1}$ ), at the three metal-doped PANI electrodes. It is evident that Sn-PANI outperforms the other counterparts with a higher atom efficiency for both $\mathrm{CO}$ and $\mathrm{HCOOH}$ formation. The TOF value is comparable with reported results for similar metal single-atom materials [43] and definitely higher than the bulk and nanostructured Sn-based catalysts [44], implying the good utilization efficiency of metal in the Sn-PANI complex.

The stability of Sn-PANI has further been investigated over 10-h $\mathrm{CO}_{2}$ electrolysis at $-0.99 \mathrm{~V}$, as shown in Fig. 7. The selectivity for $\mathrm{CO}$ and $\mathrm{HCOOH}$ formation remains quasi-stationary during the test (orange and blue squares, respectively), while the $\mathrm{FE}_{\mathrm{H} 2}$ firstly increases and then reaches a plateau (red squares). Surprisingly, the electrode activity displays a continuous growth over time (green line, current density), which could be attributed to the activation of the catalyst or the deeper wetness of the electrode. Since the selectivity is not notably changed, it is supposed that the characteristic of the catalyst is not changed either. Hence, the increase of current density is probably due to the increase

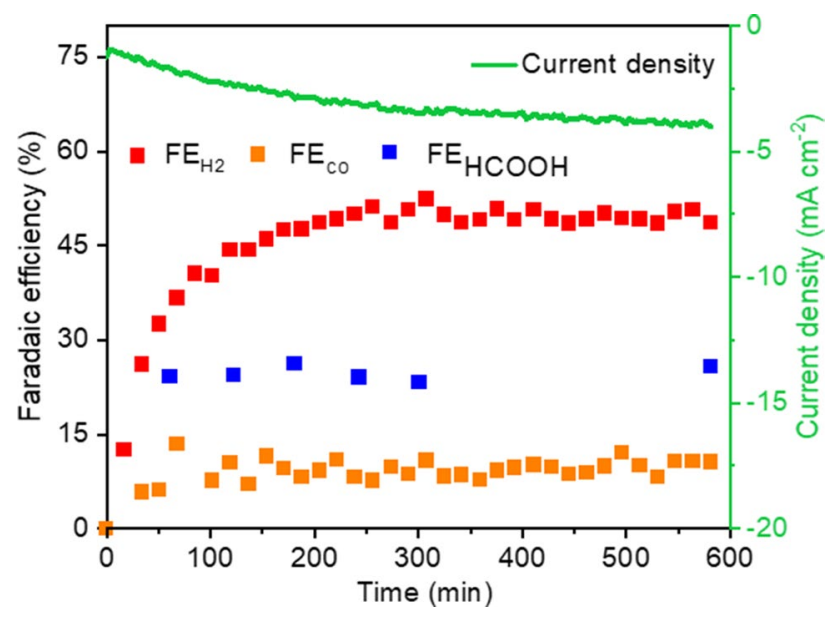

Fig. 7 Long-term test of Sn-PANI electrode. Faradaic efficiency and total current density as function of time in aqueous $\mathrm{CO}_{2}$-saturated $0.1 \mathrm{M} \mathrm{KHCO}_{3}$ solution at $-0.99 \mathrm{~V}$ of the electrode wettability that leads to higher accessibility of active sites in the electrode [45]. Further investigation is needed to concretely elucidate this point. However, it is considered a positive aspect, since the $\mathrm{CO}_{2} \mathrm{RR}$ rate is twofold enhanced during 10-h operation.

\section{Conclusions}

In summary, the investigation of the electrode composition evidences the interesting propriety of PANI-based materials to be employed without any binder or ionic conductor, thus dramatically lowering the price and simplifying the process of the electrode preparation. The binder-free electrode shows good mechanical stability and higher selectivity for the $\mathrm{CO}_{2} \mathrm{RR}$ with respect to the ones fabricated with Nafion binder. It is highlighted that an easy and novel process has been employed to anchor metal cations on PANI, resulting in new active sites for the $\mathrm{CO}_{2} \mathrm{RR}$. The metal cations of $\mathrm{Mn}, \mathrm{Cu}, \mathrm{Sn}$ and $\mathrm{Fe}$ have been investigated and show distinct characteristics, indicating the high tunability of the metalPANI complexes. Sn-PANI outperforms the other samples and exhibits good selectivity, activity and durability for the $\mathrm{CO}_{2} \mathrm{RR}$, implying its good potential to be implemented in real devices. To the best of our knowledge, the Sn-PANI is synthesized and studied as electrocatalyst for the first time and its encouraging performance implies the good potential of exploring this material for the $\mathrm{CO}_{2} \mathrm{RR}$ as well as other challenging electrochemical reactions.

Supplementary Information The online version contains supplementary material available at https://doi.org/10.1007/s10800-021-01585-7.

Author contributions The manuscript was written through contributions of all authors. All authors have given approval to the final version of the manuscript.

Funding Open access funding provided by Istituto Italiano di Tecnologia within the CRUI-CARE Agreement. This research did not receive any specific grant from funding agencies in the public, commercial, or not-for-profit sectors.

\section{Declarations}

Conflict of interest All authors declare that they have no conflict of interest.

Open Access This article is licensed under a Creative Commons Attribution 4.0 International License, which permits use, sharing, adaptation, distribution and reproduction in any medium or format, as long as you give appropriate credit to the original author(s) and the source, provide a link to the Creative Commons licence, and indicate if changes were made. The images or other third party material in this article are included in the article's Creative Commons licence, unless indicated otherwise in a credit line to the material. If material is not included in the article's Creative Commons licence and your intended use is not permitted by statutory regulation or exceeds the permitted use, you will 
need to obtain permission directly from the copyright holder. To view a copy of this licence, visit http://creativecommons.org/licenses/by/4.0/.

\section{References}

1. Gao W, Liang S, Wang R, Jiang Q, Zhang Y, Zheng Q, Xie B, Toe C, Zhu X, Wang J, Huang L, Gao Y, Wang Z, Jo C, Wang Q, Wang L, Liu Y, Louis B, Scott J, Roger AC, Amal R, He H, Park S (2020) Industrial carbon dioxide capture and utilization: state of the art and future challenges. Chem Soc Rev 49:8584-8686. https://doi.org/10.1039/D0CS00025F

2. Xiao C, Lu BA, Xue P, Tian N, Zhou ZY, Lin X, Lin WF, Sun SG (2020) High-index-facet- and high-surface-energy nanocrystals of metals and metal oxides as highly efficient catalysts. Joule 4(12):2562-2598. https://doi.org/10.1016/j.joule.2020.10.002

3. $\mathrm{Li} \mathrm{CW}$, Kanan MW (2012) $\mathrm{CO}_{2}$ reduction at low overpotential on $\mathrm{Cu}$ electrodes resulting from the reduction of thick $\mathrm{Cu} 2 \mathrm{O}$ films. J Am Chem Soc 134(17):7231-7234. https://doi.org/10.1021/ja301 0978

4. Zeng J, Bejtka K, Di Martino G, Sacco A, Castellino M, Re Fiorentin M, Risplendi F, Farkhondehfal MA, Hernández S, Cicero G, Pirri CF, Chiodoni A (2020) Microwave-assisted synthesis of copper-based electrocatalysts for converting carbon dioxide to tunable syngas. ChemElectroChem 7(1):229-238. https://doi.org/ 10.1002/celc.201901730

5. Chen Y, Fan Z, Wang J, Ling C, Niu W, Huang Z, Liu G, Chen B, Lai Z, Liu X, Li B, Zong Y, Gu L, Wang J, Wang X, Zhang H (2020) Ethylene selectivity in electrocatalytic $\mathrm{CO}_{2}$ reduction on $\mathrm{Cu}$ nanomaterials: a crystal phase-dependent study. J Am Chem Soc 142(29):12760-12766. https://doi.org/10.1021/jacs.0c04981

6. Hsieh YC, Senanayake SD, Zhang Y, Xu W, Polyansky DE (2015) Effect of chloride anions on the synthesis and enhanced catalytic activity of silver nanocoral electrodes for $\mathrm{CO}_{2}$ electroreduction. ACS Catal 5(9):5349-5356. https://doi.org/10.1021/acscatal. $5 \mathrm{~b} 01235$

7. Rosen J, Hutchings GS, Lu Q, Forest RV, Moore A, Jiao F (2015) Electrodeposited $\mathrm{Zn}$ dendrites with enhanced $\mathrm{CO}$ selectivity for electrocatalytic $\mathrm{CO}_{2}$ reduction. ACS Catal 5(8):4586-4591. https://doi.org/10.1021/acscatal.5b00922

8. Zhao S, Jin R, Jin R (2018) Opportunities and challenges in $\mathrm{CO}_{2}$ reduction by gold- and silver-based electrocatalysts: from bulk metals to nanoparticles and atomically precise nanoclusters. ACS Energy Lett 3(2):452-462. https://doi.org/10.1021/acsenergylett. 7b01104

9. Rasul S, Pugnant A, Xiang H, Fontmorin JM, Yu EH (2019) Low cost and efficient alloy electrocatalysts for $\mathrm{CO}_{2}$ reduction to formate. J CO2 Util 32:1-10. https://doi.org/10.1016/j.jcou.2019.03. 016

10. Vickers JW, Alfonso D, Kauffman DR (2017) Electrochemical carbon dioxide reduction at nanostructured gold, copper, and alloy materials. Energy Technol 5(6):775-795. https://doi.org/10.1002/ ente. 201600580

11. Ju W, Zeng J, Bejtka K, Ma H, Rentsch D, Castellino M, Sacco A, Pirri CF, Battaglia C (2019) Sn-decorated $\mathrm{Cu}$ for selective electrochemical $\mathrm{CO}_{2}$ to $\mathrm{CO}$ conversion: precision architecture beyond composition design. ACS Appl Energy Mater 2(1):867872. https://doi.org/10.1021/acsaem.8b01944

12. Zeng J, Bejtka K, Ju W, Castellino M, Chiodoni A, Sacco A, Farkhondehfal MA, Hernández S, Rentsch D, Battaglia C, Pirri $\mathrm{CF}$ (2018) Advanced $\mathrm{Cu}-\mathrm{Sn}$ foam for selectively converting $\mathrm{CO}_{2}$ to $\mathrm{CO}$ in aqueous solution. Appl Catal B Environ 236:475-482. https://doi.org/10.1016/j.apcatb.2018.05.056
13. Deloitte Sustainability, British Geological Survey, Bureau de Recherches Géologiques et Minières, Netherlands Organisation for Applied Scientific Research (2017) Study on the review of the list of Critical Raw Materials- Criticality Assessments. Publications Office of the European Union, Luxembourg, ISBN 978-9279-47937-3. https://doi.org/10.2873/876644

14. Han L, Song S, Liu M, Yao S, Liang Z, Cheng H, Ren Z, Liu W, Lin R, Qi G, Liu X, Wu Q, Luo J, Xin HL (2020) Stable and efficient single-atom $\mathrm{Zn}$ catalyst for $\mathrm{CO}_{2}$ reduction to $\mathrm{CH}_{4}$. J Am Chem Soc 142(29):12563-12567. https://doi.org/10.1021/jacs. $9 \mathrm{~b} 12111$

15. Nguyen TN, Salehi M, Le QV, Seifitokaldani A, Dinh CT (2020) Fundamentals of electrochemical $\mathrm{CO}_{2}$ reduction on single-metalatom catalysts. ACS Catal 10(17):10068-10095. https://doi.org/ 10.1021/acscatal.0c02643

16. Li M, Wang H, Luo W, Sherrell PC, Chen J, Yang J (2020) Heterogeneous single-atom catalysts for electrochemical $\mathrm{CO}_{2}$ reduction reaction. Adv Mater 32(34):2001848. https://doi.org/10.1002/ adma.202001848

17. Ghosh AC, Duboc C, Gennari M (2020) Synergy between metals for small molecule activation: enzymes and bio-inspired complexes. Coord Chem Rev 428:213606. https://doi.org/10.1016/j. ccr.2020.213606

18. Torbensen K, Boudy B, Joulié D, Wolff NV, Robert M (2020) Emergence of $\mathrm{CO}_{2}$ electrolyzers including supported molecular catalysts. Curr Opin Electrochem 24:49-55. https://doi.org/10. 1016/j.coelec.2020.07.001

19. Francke R, Schille B, Roemelt M (2018) Homogeneously catalyzed electroreduction of carbon dioxide-methods, mechanisms, and catalysts. Chem Rev 118(9):4631-4701. https://doi.org/10. 1021/acs.chemrev.7b00459

20. Zheng W, Nayak S, Yuan W, Zeng Z, Hong X, Vincent KA, Tsang SCE (2016) A tunable metal-polyaniline interface for efficient carbon dioxide electro-reduction to formic acid and methanol in aqueous solution. Chem Commun 52(96):13901-13904. https:// doi.org/10.1039/C6CC07212G

21. Wei X, Yin Z, Lyu K, Li Z, Gong J, Wang G, Xiao L, Lu J, Zhuang $\mathrm{L}$ (2020) Highly selective reduction of $\mathrm{CO}_{2}$ to $\mathrm{C}_{2+}$ hydrocarbons at $\mathrm{Cu} /$ polyaniline interfaces. ACS Catal 10(7):4103-4111. https:// doi.org/10.1021/acscatal.0c00049

22. Varela AS, Ju W, Bagger A, Franco P, Rossmeisl J, Strasser P (2019) Electrochemical reduction of $\mathrm{CO}_{2}$ on metal-nitrogen-doped carbon catalysts. ACS Catal 9(8):7270-7284. https://doi.org/10. 1021/acscatal.9b01405

23. Varela AS, Kroschel M, Leonard ND, Ju W, Steinberg J, Bagger A, Rossmeisl J, Strasser P (2018) PH effects on the selectivity of the electrocatalytic $\mathrm{CO}_{2}$ reduction on graphene-embedded $\mathrm{Fe}-$ $\mathrm{N}-\mathrm{C}$ motifs: bridging concepts between molecular homogeneous and solid-state heterogeneous catalysis. ACS Energy Lett 3(4):812-817. https://doi.org/10.1021/acsenergylett.8b00273

24. Bocchini S, Chiolerio A, Porro S, Accardo D, Garino N, Bejtka K, Perrone D, Pirri CF (2013) Synthesis of polyaniline-based inks, doping thereof and test device printing towards electronic applications. J Mater Chem C 1(33):5101-5109. https://doi.org/10.1039/ c3tc30764f

25. Chiolerio A, Bocchini S, Crepaldi M, Bejtka K, Pirri CF (2017) Bridging electrochemical and electron devices: fast resistive switching based on polyaniline from one pot synthesis using $\mathrm{FeCl}_{3}$ as oxidant and Co-doping agent. Synth Met 229:72-81. https:// doi.org/10.1016/j.synthmet.2017.05.001

26. Shirley DA (1972) High-resolution X-ray photoemission spectrum of the valence bands of gold. Phys Rev B 5:4709. https://doi.org/ 10.1103/PhysRevB.5.4709

27. Bocchini S, Castellino M, Della Pina C, Rajan K, Falletta E, Chiolerio A (2018) Inkjet printed doped polyaniline: navigating 
through physics and chemistry for the next generation devices. Appl Surf Sci 456:246-258. https://doi.org/10.1016/j.apsusc. 2018.06.003

28. Kumar SN, Gaillard F, Bouyssoux G, Sartre A (1990) High-resolution XPS studies of electrochemically synthesized conducting polyaniline films. Synth Met 36(1):111-127. https://doi.org/10. 1016/0379-6779(90)90240-L

29. Vasquez RP (1993) CuCl by XPS. Surf Sci Spectra 2(2):138-143. https://doi.org/10.1116/1.1247732

30. Biesinger MC (2017) Advanced analysis of copper X-ray photoelectron spectra. Surf Interface Anal 49(13):1325-1334. https:// doi.org/10.1002/sia.6239

31. Xu H, Zhang J, Chen Y, Lu H, Zhuang J (2014) Electrochemical polymerization of polyaniline doped with $\mathrm{Cu}^{2+}$ as the electrode material for electrochemical supercapacitors. RSC Adv 4(11):5547-5552. https://doi.org/10.1039/c3ra45794j

32. Vasnin S, Geanangel RA (1989) Adducts of Tin(II) chloride with imidazole and methylimidazoles. Inorganica Chim Acta 160(2):167-170. https://doi.org/10.1016/S0020-1693(00)80581-2

33. Nesbitt HW, Banerjee D (1998) Interpretation of XPS Mn(2p) spectra of Mn oxyhydroxides and constraints on the mechanism of $\mathrm{MnO}_{2}$ precipitation. Am Mineral 83:305-315. https://doi.org/ 10.2138/am-1998-3-414

34. Biesinger MC, Payne BP, Grosvenor AP, Lau LWM, Gerson AR, Smart RSC (2011) Resolving surface chemical states in XPS analysis of first row transition metals, oxides and hydroxides: $\mathrm{Cr}$, Mn, Fe, Co and Ni. Appl Surf Sci 257(7):2717-2730. https://doi. org/10.1016/j.apsusc.2010.10.051

35. Grosvenor AP, Kobe BA, Biesinger MC, McIntyre NS (2004) Investigation of multiplet splitting of Fe $2 p$ XPS spectra and bonding in iron compounds. Surf Interface Anal 36(12):1564-1574. https://doi.org/10.1002/sia.1984

36. Xu H, Wu J, Li C, Zhang J, Liu J (2015) Investigation of polyaniline films doped with $\mathrm{Fe}^{3+}$ as the electrode material for electrochemical supercapacitors. Electrochim Acta 165:14-21. https:// doi.org/10.1016/j.electacta.2015.01.224

37. Yoon SB, Yoon EH, Kim KB (2011) Electrochemical properties of leucoemeraldine, emeraldine, and pernigraniline forms of polyaniline/multi-wall carbon nanotube nanocomposites for supercapacitor applications. J Power Sources 196(24):10791-10797. https:// doi.org/10.1016/j.jpowsour.2011.08.107
38. Gul S, Shah AUHA, Bilal S (2013) Synthesis and characterization of processable polyaniline salts. J Phys: Conf Ser 439:012002. https://doi.org/10.1088/1742-6596/439/1/012002

39. Izumi CMS, Rodrigues DC, Pelaes LAG, Da Costa Ferreira AM, Temperini MLA (2016) Influence of different copper(II) salts on the oxidation and doping reactions of emeraldine base polyaniline. Vib Spectrosc 87:129-136. https://doi.org/10.1016/j.vibsp ec.2016.09.019

40. Jhong HRQ, Brushett FR, Kenis PJA (2013) The effects of catalyst layer deposition methodology on electrode performance. Adv Energy Mater 3(5):589-599. https://doi.org/10.1002/aenm.20120 0759

41. Ott S, Orfanidi A, Schmies H, Anke B, Nong HN, Hübner J, Gernert U, Gliech M, Lerch M, Strasser P (2020) Ionomer distribution control in porous carbon-supported catalyst layers for high-power and low Pt-loaded proton exchange membrane fuel cells. Nat Mater 19(1):77-85. https://doi.org/10.1038/s41563-019-0487-0

42. Bejtka K, Zeng J, Sacco A, Castellino M, Hernández S, Farkhondehfal MA, Savino U, Ansaloni S, Pirri CF, Chiodoni A (2019) Chainlike mesoporous $\mathrm{SnO}_{2}$ as a well-performing catalyst for electrochemical $\mathrm{CO}_{2}$ reduction. ACS Appl Energy Mater 2(5):3081-3091. https://doi.org/10.1021/acsaem.8b02048

43. Ju W, Bagger A, Hao GP, Varela AS, Sinev I, Bon V, Roldan Cuenya B, Kaskel S, Rossmeisl J, Strasser P (2017) Understanding activity and selectivity of metal-nitrogen-doped carbon catalysts for electrochemical reduction of $\mathrm{CO}_{2}$. Nat Commun 8(1):1-9. https://doi.org/10.1038/s41467-017-01035-Z

44. Zhao S, Li S, Guo T, Zhang S, Wang J, Wu Y, Chen Y (2019) Advances in Sn-based catalysts for electrochemical $\mathrm{CO}_{2}$ reduction. Nano-Micro Lett 11:62. https://doi.org/10.1007/ s40820-019-0293-x

45. Kolyagin GA, Kornienko VL (2018) Effect of electric current on the wettability of carbon-containing gas diffusion electrodes by aqueous solutions and the change in their capacitance characteristics. Russ J Electrochem 54(12):1288-1293. https://doi.org/10. 1134/S1023193518130220

Publisher's Note Springer Nature remains neutral with regard to jurisdictional claims in published maps and institutional affiliations.

\section{Authors and Affiliations}

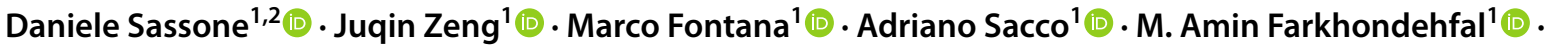 Monica Periolatto ${ }^{2}$ (]) . Candido F. Pirri ${ }^{1,2}$ (D) Sergio Bocchini ${ }^{1}[$}

1 Center for Sustainable Future Technologies (CSFT)@ Polito, Istituto Italiano Di Tecnologia, Via Livorno 60, 10144 Torino, Italy
Department of Applied Science and Technology_DISAT, Politecnico Di Torino, Corso Duca degli Abruzzi 24, 10129 Torino, Italy 